\title{
Inflammatory diseases of the parathyroid gland
}

\author{
Nadia Talat, Salvador Diaz-Cano ${ }^{1} \&$ Klaus-Martin Schulte \\ Departments of Endocrine Surgery and ${ }^{1}$ Histopathology, King's College Hospital NHS Foundation Trust and King's Health \\ Partners, London, UK
}

Date of submission 13 May 2011

Accepted for publication 14 July 2011

Talat N, Diaz-Cano S \& Schulte K-M

(2011) Histopathology 59, 897-908

\section{Inflammatory diseases of the parathyroid gland}

Aims: Inflammatory disorders of the parathyroid gland are very rare as compared with those of other endocrine organs. The aim of this study was to provide the first systematic review of this condition.

Methods and results: A 42-year-old patient underwent surgery for recurrent secondary hyperparathyroidism. Histology showed hyperplastic parathyroiditis defined by a mixed inflammatory infiltrate with active germinal centres. Molecular markers revealed significant upregulation of CD68 in an ischaemic background (hypoxiainducible factor 1 upregulation) with mitochondrial reaction (malate dehydrogenase 2 upregulation) and hyperparathyroidism (carbonic anhydrase 4 upregulation). Our case demonstrates true intraparathyroid inflammation with terminal B-cell differentiation. We searched PubMed, ISI Thompson and Google Scholar up to January 2011, using the terms 'parathyroiditis', 'inflammation of parathyroid gland', 'lymphocytic infiltrate', 'tuberculosis of the parathyroid', 'sarcoidosis', and 'graulomatous inflammation'. Three autopsy series, 27 articles and 96 case reports with inflammatory parathyroid disorders were identified. Autopsy series showed lymphocytic infiltrates in up to $16 \%$ of all cases. The entire material reported lymphocytic infiltrates $(n=69)$, parathyroiditis with germinal centres $(n=15)$, sarcoidosis $(n=6)$, tuberculosis $(n=4)$, and other granulomatous diseases $(n=2)$.

Conclusions: Distinct inflammatory and granulomatous processes in the parathyroid gland are rare. Scanty lymphocytic infiltrates are common, and occur in generalized inflammatory conditions or venous congestion. We note the surprising absence of an association between histological proof of parathyroiditis and hypoparathyroidism.

Keywords: inflammation, lymphocytic infiltrate, parathyroid gland, parathyroiditis, primary hyperparathyroidism

Abbreviations: CA4, carbonic anhydrase 4; CT, computed tomography; GAPDH, glyceraldehyde-3-phosphate dehydrogenase; HIF1A, hypoxia-inducible factor 1A; M6PR, mannose 6-phosphate receptor; MDH2, malate dehydrogenase 2; MGB, minor groove binder; PCR, polymerase chain reaction; PTH, parathyroid hormone; RT, reverse transcription

\section{Introduction}

Inflammatory disorders of the parathyroid gland are rare as compared with those of other endocrine organs. ${ }^{1-4}$ These entities are poorly defined, and descriptive terms such as lymphocytic infiltrate, parathyroiditis and lymphocytic parathyroiditis are used, resulting in no agreed scheme of classification.

Address for correspondence: K-M Schulte, Department of Endocrine Surgery, King's College Hospital, Kings Health Partners, King's College London, London SE5 9RS, UK.

e-mail: klaus-martin.schulte@nhs.net
Inflammation in other endocrine organs such as the thyroid has a long list of notable clinical associations. Thyroiditis, for example, is known to be associated with hypothyroidism, goitres, thyrotoxicosis, and hashitoxicosis, ${ }^{5,6}$ but no such clinical associations have been defined for parathyroid inflammatory disorders. Thyroiditis is associated with severe disturbances in thyroid function, with inflammatory effects ranging from thyrotoxicosis resulting from hormone releasing thyroiditis to chronic subclinical and clinical hypothyroidism, when the gland is transformed into a scar. With regard to parathyroid inflammation, very little is known about its effects on parathyroid function. A 
number of studies have demonstrated autoimmune hypoparathyroidism; however, none has shown histological evidence of inflammatory processes within the parathyroids as is seen in parathyroiditis. ${ }^{7-9}$

Because of this terminological variation and the paucity of recent studies, it is not generally clear how to classify inflammatory parathyroid entities. It is also not clear whether such descriptive nosological entities relate to specific clinical constellations. This article is aimed at clarifying the pathological presentations and their clinical associations by using findings from an index patient with hyperplastic parathyroiditis; the molecular markers of this lesion are compared with a set of normal parathyroid glands, hyperplasias, and adenomas. We have therefore attempted to improve our understanding of these rare conditions by a review of the literature. It also makes minor contributions to our understanding of functional aspects of inflammatory parathyroid disease.

\section{Materials and methods}

A systematic search was conducted of the published literature on inflammatory diseases of the parathyroid gland. The databases searched included PubMed (http://www.ncbi.nlm.nih.gov/pubmed/), Thompson ISI (http://apps.isiknowledge.com/) and Google Scholar; the search terms used were 'parathyroiditis', 'inflammation of parathyroid gland', 'lymphocytic infiltrate', 'tuberculosis', 'sarcoidosis', and 'granulomatous inflammation'. A hand search of article bibliographies was also performed with the ISI Thompson Web of Knowledge Citation report, enabling further articles to be retrieved. From the initial electronic search of 185 articles for possible inclusion, 27 articles were retained following title and abstract reviews; these articles reported on a total of 96 patients with inflammatory diseases of the parathyroid gland, including parathyroiditis $(n=15)$, lymphocytic infiltrate $(n=69)$, sarcoidosis of the parathyroid gland $(n=6)$, tuberculosis $(n=14)$, and granulomatous disease $(n=2) .{ }^{10-36}$ The inclusion criterion was unambiguous evidence of inflammatory processes of the parathyroid gland in the form of a histological description.

Histopathological descriptions were evaluated from the author's summary diagnosis and by analysing the information provided by the authors regarding the presence of lymphocytic infiltrate, parathyroiditis, and granulomatous inflammation. The terminology for parathyoiditis was inconsistent. After review of all histological descriptions, we found two fundamentally different patterns, and grouped patients according to these descriptions:
1. The non-specific pattern is marked by diffuse lymphocytic infiltrates in the direct vicinity of venules without evidence of lymphocyte maturation or immune-mediated tissue damage, such as fibrosis or epithelial degeneration.

2 . The pattern of lymphocytic parathyroiditis is characterized by interstitial lymphocytes away from the vessels with terminal differentiation (plasma cells) and/or formation of germinal centres.

Data were extracted by one researcher and checked by another with standardized extraction tables developed a priori. Data were pooled as individual cases in a single contingent sPss table.

\section{PATIENT}

This 42-year-old male Caucasian patient suffered from end-stage renal failure resulting from hyperplastic kidney that he had suffered from since 1995, when he was put on continuous ambulatory peritoneal dialysis. He developed severe secondary hyperparathyroidism with fatigue and bone pain, failed on calcimimetics, and underwent a total cervical parathyroidectomy with central lymph node clearance and thymectomy in 2007. Histopathology demonstrated four parathyroid glands with nodular hyperplasia, weighing $4.96 \mathrm{~g}, 1.64 \mathrm{~g}, 1.23 \mathrm{~g}$, and $0.71 \mathrm{~g}$. Two lymph nodes showed only reactive changes; the thymus and mediastinal fat resection weighed $125.5 \mathrm{~g}$, and were histologically normal. Postoperatively, the parathyroid hormone (PTH) level dropped to $97 \mathrm{ng} / \mathrm{l}$ (normal 13-75 ng/l) in the presence of a low normal corrected calcium level of $2.29 \mathrm{~mm}$ and a normal phosphate level (Figure 1). The presence of PTH at this point was explained by the $60-\mathrm{mg}$ parathyroid autotransplant into the forearm extensor muscles. An increase in the PTH level to $>10$-fold upper normal levels, with recurrent fatigue and bone aches, led to excision of the autotransplant from the left forearm after negative imaging findings in the neck and chest. This revealed $1.99 \mathrm{~g}$ of nodular parathyroid hyperplasia. The postoperative PTH levels dropped to $52 \mathrm{ng} / \mathrm{l}$, in the presence of a normal corrected calcium level supported by high-dose active vitamin D treatment. Over the subsequent 2 years, the patient showed extreme fluctuations of PTH levels between the upper normal limit of $70 \mathrm{ng} / \mathrm{l}$ and $2000 \mathrm{ng} / \mathrm{l}$ with concordant fluctuations in symptomatology. Complex reimaging with ultrasound and magnetic resonance imaging of the neck, contrast computed tomography (CT) of the neck and chest and fusion imaging including Technetium Tc 99m sestamibi single-photon emission computed tomography (MIBI-SPECT) sug- 

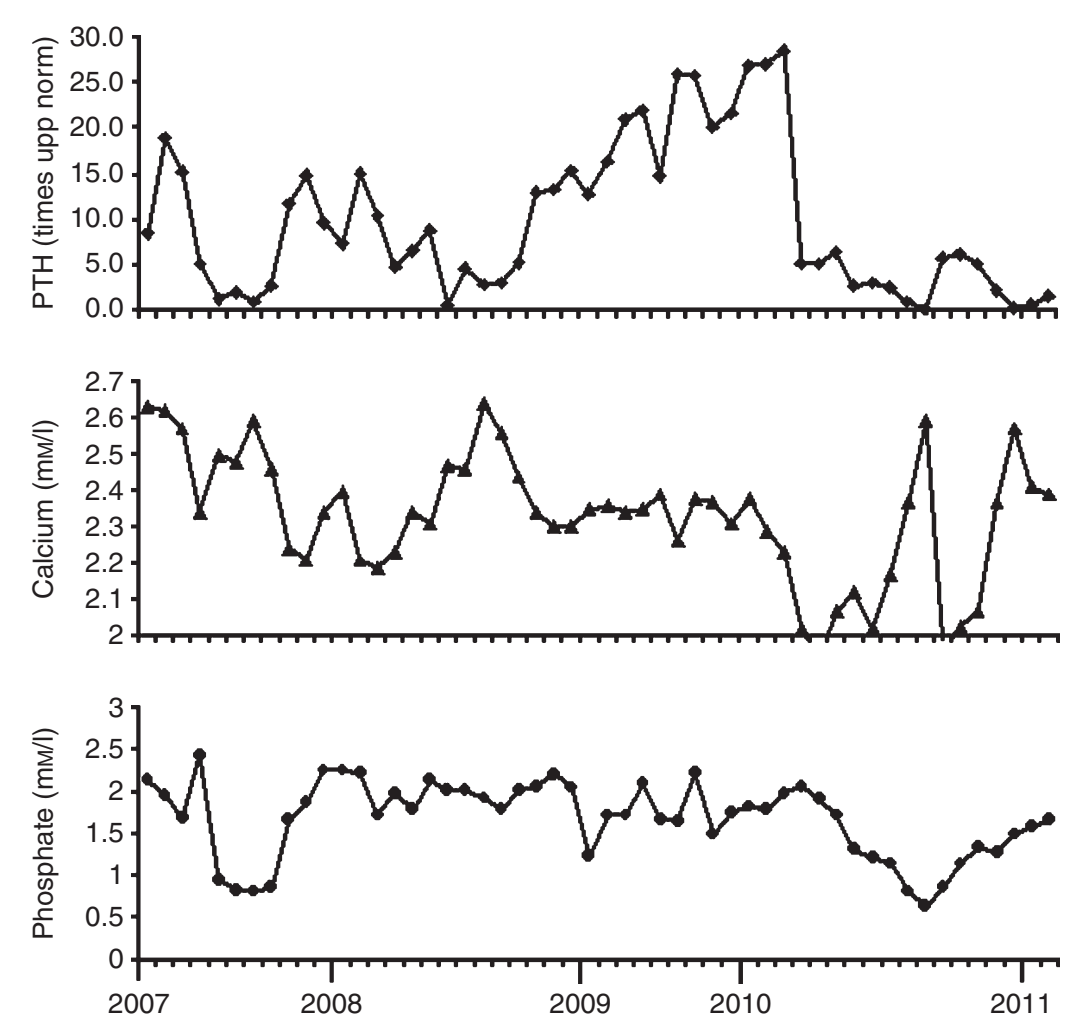

Figure 1. The clinical course of our case with parathyroiditis. Parathyroid hormone (PTH) levels are expressed as times the upper normal limit of the methods used, as two different assays were used to obtain PTH measurements for this patient. Calcium normal (2.15-2.60 mu); phosphate normal (0.80-1.40 mM).

gested a 1-cm lesion riding the aortic arch. In July 2010, initial thoracoscopic exploration showed this to be a probable tuberculous lymph node, and surgery was therefore changed to thoracotomy with exploration of the aortopulmonary window. The surgery was followed by normalization of the PTH and calcium levels. The specimen measured $35 \times 19 \times 21 \mathrm{~mm}$ and weighed $6 \mathrm{~g}$. It showed a nodular growth pattern composed of oncocytic and clear cell islands. The stroma was expanded by a prominent diffuse and patchy mixed inflammatory infiltrate, comprising mainly plasma cells and lymphocytes. There was interstitial haemorrhage, congestion, and large numbers of haemosiderin-laden macrophages. There was no vascular invasion, confluent necrosis, or undue mitotic activity. The features were consistent with hyperplastic parathyroiditis (Figures 2 and 3).

\section{TARGETED GENE EXPRESSION ANALYSIS}

Total RNA was isolated from control parathyroid glands ( $n=5$, from thyroidectomies with no parathyroid pathology), hyperplasias $(n=10)$, and adenomas $(n=10)$, by the use of commercial kits (RNeasy kit;

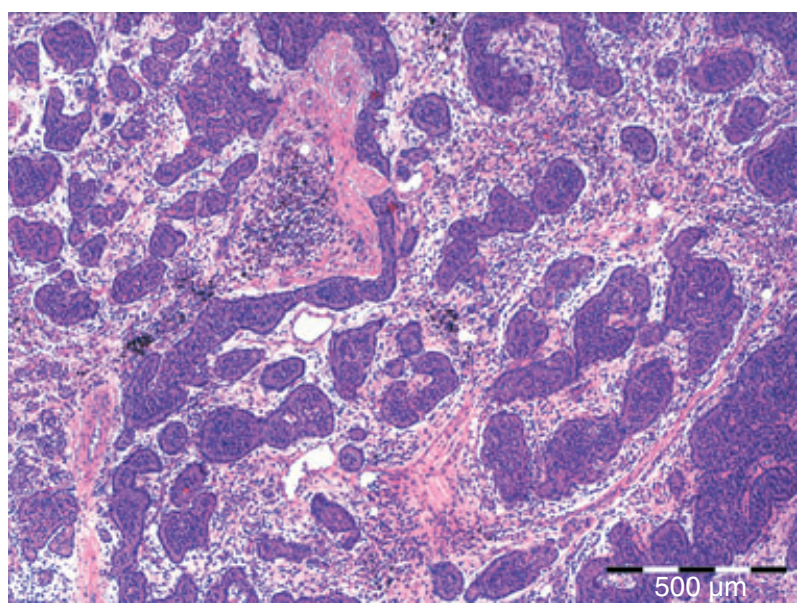

Figure 2. Parathyroid tissue reveals thick trabeculae of chief cells dissected by inflamed stroma with dilated blood vessels and haemosiderin-laden macrophages (haematoxylin and eosin, $\times 40$ ).

Qiagen, Crawley, UK), following the manufacturer's instructions. After extraction, the RNA was treated with DNaseI (DNA-free; Ambion, Austin, TX, USA) at $37^{\circ} \mathrm{C}$ for $20 \mathrm{~min}$ in a $50-\mu \mathrm{l}$ reaction containing total RNA in water, $5 \mu \mathrm{l}$ of DNA-free buffer, $2 \mu \mathrm{l}$ of Superase 

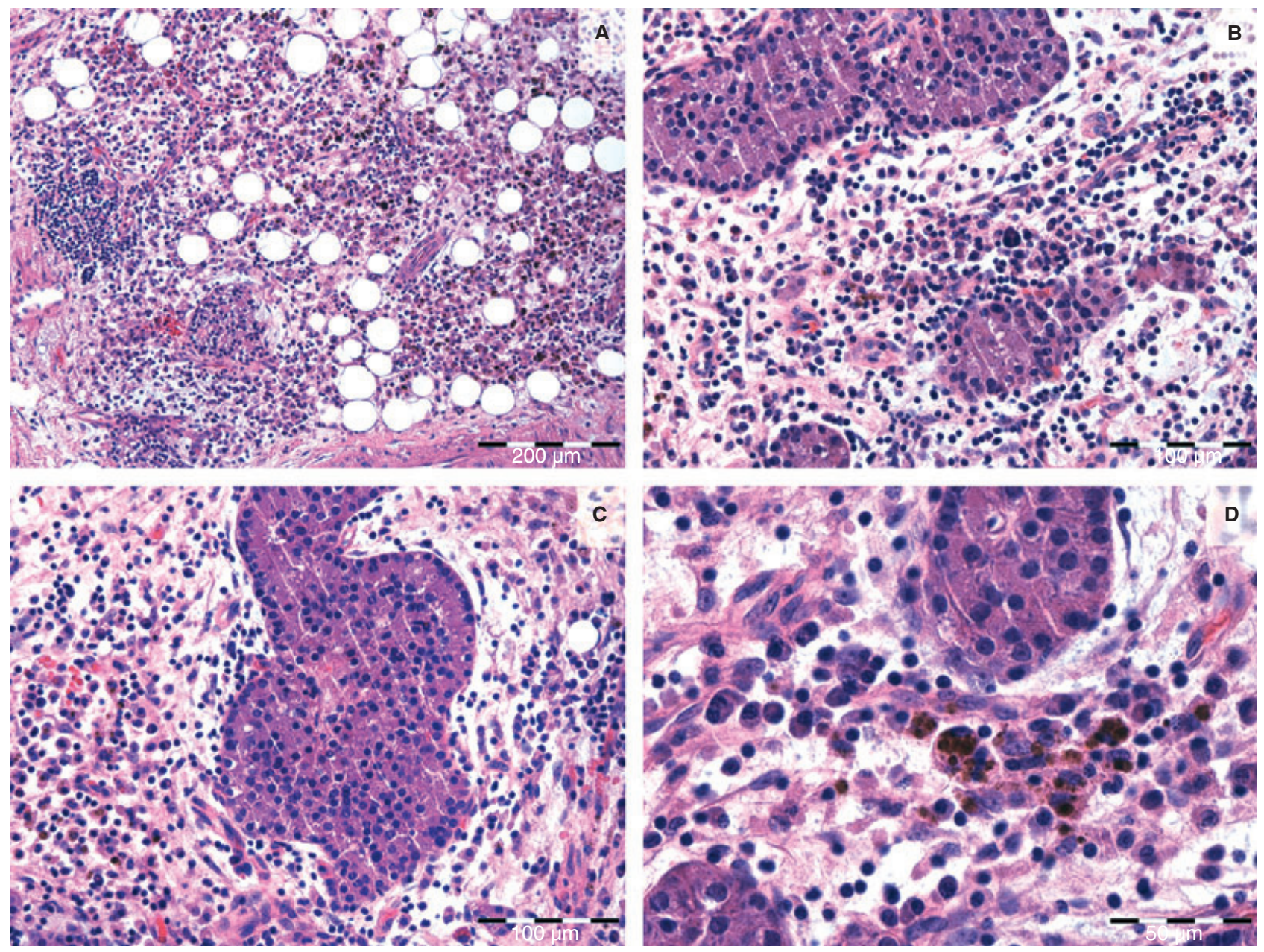

Figure 3. Chronic parathyroiditis reveals interstitial chronic inflammation with focal degenerative changes [fat infiltration, A, haematoxylin and eosin (H\&E), $\times 100]$ as indicated by tissue damage, cell infiltrate containing mature plasma cells (antigen-driven terminally differentiated B cells, B, H\&E, $\times 200)$, and increased vascular permeability with red blood cell extravasation, both recent $($ C, H\&E, $\times 200)$ and chronic (siderophages, D, H\&E, $\times 400$ ).

RNAse inhibitor (Ambion), and $1 \mu \mathrm{l}$ of DNaseI. To clean up the RNA, the mixture was loaded onto an RNeasy column and total RNA was eluted with water in a volume of $40 \mu \mathrm{l}$. The quantity and quality of the RNA samples were determined with the RNA 6000 LabChip kit (Agilent Technologies, Wilmington, DE, USA).

\section{Reverse transcription}

Reverse transcription (RT) was carried out in a 20- $\mu$ l reaction volume containing $1 \times$ PCR buffer II (PE Biosystems, Foster City, CA, USA), 25 units of Moloney murine leukaemia virus reverse transcriptase (SuperScript II; Life Technologies, Carlsbad, CA, USA), 8 units of RNase inhibitor (PE Biosystems), $7.5 \mathrm{~mm} \mathrm{MgCl}_{2}$, $1.0 \mathrm{~mm}$ each 2-deoxynucleotide 5'-triphosphate (Roche Molecular Biochemicals, Indianapolis, IN, USA), $2.5 \mu \mathrm{M}$ random hexamers (PE Biosystems), and $30 \mathrm{ng}$ of total RNA. RT was performed by incubating the samples at $25^{\circ} \mathrm{C}$ for $10 \mathrm{~min}, 48^{\circ} \mathrm{C}$ for $40 \mathrm{~min}$ and $95^{\circ} \mathrm{C}$ for $5 \mathrm{~min}$ in a PerkinElmer GeneAmp PCR System 9700. No-RT controls were carried out in all cases by using the same RT reaction mixture but substituting diethylpyrocarbonate- $\mathrm{H}_{2} \mathrm{O}$ for the reverse transcriptase. For all quantitative analyses, two RT reactions were carried out for each RNA sample by using 200 and 50 ng per $100 \mu \mathrm{l}$ of RT reaction mixture. The no-RT controls were carried out with $200 \mathrm{ng}$ of RNA.

Real-time quantitative polymerase chain reaction (PCR) Quantitative real-time PCR is based on the detection of a fluorescent signal that increases linearly with accumulating amplification product during the PCR reaction. During the extension phase of PCR, the probe is 
cleaved by the endogenous $5^{\prime}$-nuclease activity of AmpliTaq Gold polymerase, which cleaves the reporter chromophor from the TaqMan probe, leading to an increase in the intensity of reporter fluorescence. The increase in fluorescence $(\Delta \mathrm{Rn})$ signal is continuously measured and plotted versus PCR cycle number, reflecting the amount of PCR amplification product. The ABI PRISM 7700 detection system software (Applied Biosystems, Foster City, CA, USA) calculates $\Delta \mathrm{Rn}$ by subtracting the fluorescence signal of the baseline emission during cycles 3-6 from the fluorescence signal of the product at any given time. A threshold was set at the early log phase of product accumulation. The threshold cycle number value $\left(C_{\mathrm{T}}\right)$ is the cycle number at which each sample's amplification plot reaches this threshold. We carried out real-time PCR with TaqMan unlabeled PCR primers and 6-carboxyfluorescein dyelabelled TaqMan minor groove binder (MGB; 6-carboxytetramethylrhodamine) primer probes on an ABI PRISM 7700 Sequence Detection System (Applied Biosystems). The MGB probes have an MGB at the $3^{\prime}$-end of the probe, which increases the $T_{\mathrm{m}}$ of probes, allowing the use of shorter probes. PCR primers and fluorogenic probes (TaqMan) were designed by using Primer EXPRESS software (PE Biosystems). All primer sequences are given in Table 1. Wherever possible, primers and probes were designed to span introns in the genomic DNA, thereby minimizing the potential for confounding of the signal by contaminating genomic DNA. TaqMan primers and MGB probes for target genes (Table 1) were obtained from Assays on Demand (Applied Biosystems). Glyceraldehyde-3-phosphate dehydrogenase (GAPDH) TaqMan primers and MGB probes were obtained as pre-developed assay reagents from Applied Biosystems. PCR reactions were performed in 25- $\mu \mathrm{l}$ volumes consisting of $1 \times$ PCR buffer A (PE Biosystems), $3.5 \mathrm{~mm} \mathrm{MgCl}_{2}, 300 \mu \mathrm{m}$ each dATP, dCTP, dGTP, and dTTP, 1.25 units of AmpliTaq Gold (PE Biosystems), and $2.5 \mu \mathrm{l}$ of the appropriate RT reaction product. The primers were present at $300 \mathrm{~nm}$, and the TaqMan probe was present at $200 \mathrm{~nm}$. The GAPDH amplification primers were each present at $100 \mathrm{~nm}$, and the TaqMan probe was present at $100 \mathrm{~nm}$. Amplification and detection were carried out by using an ABI 7700 detection system as follows: one cycle at $95^{\circ} \mathrm{C}$ for $12 \mathrm{~min}, 40$ cycles at $95^{\circ} \mathrm{C}$ for $15 \mathrm{~s}$, and $60^{\circ} \mathrm{C}$ for $1 \mathrm{~min}$. All cases were conducted with duplicate samples and $C_{\mathrm{T}}$ units obtained as the average of the results from the replicates. $C_{\mathrm{T}}$ is defined as the threshold cycle for PCR amplification that is detected by the ABI PRISM DNA sequence detector at a threshold value set at 0.45 for each run. The calculated $C_{\mathrm{T}}$ values were analysed in Microsoft Excel.

\section{Calculation of relative expression}

Relative mRNA expression of target genes was calculated with the comparative $C_{\mathrm{T}}$ method. The amount of target gene was normalized to the endogenous GAPDH control gene to control for quantity of RNA input. The difference in $C_{\mathrm{T}}$ values was calculated for each mRNA by taking the mean $\mathcal{C}_{\mathrm{T}}$ of duplicate reactions and subtracting the mean $C_{\mathrm{T}}$ of duplicate reactions for reference RNA measured on an aliquot from the same RT reaction: $\Delta C_{\mathrm{T}}=C_{\mathrm{T}}($ target gene $)-C_{\mathrm{T}}(G A P D H)$. A logarithmic transformation was used to graphically tabulate the data.

\section{Results}

There were two large autopsy studies specifically addressing the issue of parathyroiditis, one comprising 225 patients $^{10}$ and one containing 589 patients, $^{36}$ in whom 1637 parathyroid glands were dissected. Both studies were based on unselected autopsy cohorts, with male patients accounting for $51.1 \%$ and $57.0 \%$, respectively. Seemann's study revealed two patients

Table 1. Primer sequences

\begin{tabular}{lll}
\hline Gene & Forward primer $\left(5^{\prime}-3^{\prime}\right)$ & Reverse primer $\left(5^{\prime}-3^{\prime}\right)$ \\
\hline CA4 & TCGGAGCACAGCCTCGAT & CTCGATGTCCCCTTCTCTTTCTC \\
\hline CD68 & GCAGAAGCTGGGTGTCATAGG & CACGGAGGATGCGGTCTTAT \\
\hline MDH2 & GAGGCCTGGGGCATCTCTGTA & CGAGTTGCTGCAACTGAAGCT \\
\hline HIF1A & CCGCCTGACCCTCTATGATATCC & TCCGGCTTTAGCCTTGACCAC \\
\hline
\end{tabular}

CA4, Carbonic anhydrase 4; HIF1A, hypoxia-inducible factor $1 A ; M 6 P R$, mannose 6-phosphate receptor; $M D H 2$, malate dehydrogenase 2 . 
with secondary hyperparathyroidism, no patient with known primary hyperparathyroidism, and no patient with clinical hypoparathyroidism. Seemann described lymphocytic infiltrates, perivenular in distribution, in 38 cases $(16.9 \%)$. Only seven of the cases showed interstitial infiltrates. Fifteen cases showed only isolated and small accumulation of lymphoid cells, 18 cases showed larger groups of cells, and only five cases showed several large cell clusters. In only one case did the lymphocytic infiltrate involve all four glands (the patient died from myocardial infarction). The infiltrate was predominantly lymphocytic in 27 cases, lymphoplasmacytic in four cases, predominantly plasmacytic in three cases, and mixed (plasma cells, lymphocytes, and histocytes) in four cases. The underlying conditions comprised severe systemic inflammation such as septicaemia, pneumonia, purulent meningitis, pyelonephritis, and endocarditis (22 cases), and recent extensive myocardial infarctions (six cases). There was a single case of disseminated tuberculosis. This patient also showed caseating granulomas within the parathyroid gland, along with multiple perivascular lymphocytic infiltrates. This article's conclusions highlighted only one patient with true lymphocytic parathyroiditis in a patient with myocardial infarction, and proposed an autoimmune process.

The Thiele study showed 10 patients with secondary hyperparathyroidism, but no cases of primary hypoparathyroidism/hyperparathyroidism. It focused mostly on the problem of transition between diffuse and nodular hyperplasia and adenoma. The article described four patients with purulent destruction of parathyroid parenchyma in the setting of septicaemia or continuity from infected tracheostomies. It also described diffuse lymphocytic infiltrates in an unknown number of patients, but these findings were dismissed. The article concluded that no single case of true lymphocytic parathyroiditis was observed. The results of the autopsies studies are summarized in Table 2.

Table 3 gives clinical details of the 15 cases of parathyroiditis identified from the literature. All patients included had clear histological evidence of the disease, as described above. We reclassified three cases, described by the authors as lymphocyic infiltrate of the parathyroid gland, as histologically consistent with parathyroiditis. These patients were therefore reclassified as having parathyroiditis. Apart from the autopsy studies, all other patients showed parathyroid hyperfunction.

In surgical pathology material, only five case reports mentioned the presence of lymphocytic infiltrate of the parathyroid gland in patients with primary hyperparathyroidism. All patients $(5,100 \%)$ were found to have a parathyroid adenoma (Table 4). Associated diseases were found in two of four $(50 \%$; one case had no data available). Associated diseases were far more common in the single autopsy cases $(5 / 7,71 \%)$ (Table 4$)$. Table 6 shows that associated diseases were much more common in patients with simple lymphocytic infiltrate of the parathyroid gland $(73.9 \%)$ than in patients with parathyroiditis $(31.2 \%)\left(\chi^{2} 11.1, P=0.001\right)$. Granulomatous disease of the parathyroid gland is surprisingly rare. Only 11 cases have been identified, and the clinical details of these are outlined in Table 5.

The relative gene expression for each marker is shown in Figure 4. All markers for our case of hyperplastic parathyroiditis were in the range of hyperplastic-adenomatous lesions of the parathyroid gland, with the exception of CD68, which was significantly upregulated, reflecting the presence of histiocytic infiltrate [also supported by mannose 6-phosphate receptor $(M 6 P R)$ upregulation]. Hypoxia-inducible factor $1 \mathrm{~A}(\mathrm{HIF} 1 \mathrm{~A})$ and malate dehydrogenase $2(\mathrm{MDH} 2)$ upregulation suggested an ischaemic background and a reactive mitochondrial process. The upregulated carbonic anhydrase 4 (CA4) expression is consistent with hyperparathyroidism.

\section{Discussion}

The term parathyroiditis has been used with some inconsistency. Some authors use it to describe any lymphocytic infiltrate in the parathyroid gland, whereas others employ it as a specific term for evidence of an immune process residing in the parathyroid gland. ${ }^{36}$ Other authors use the term lymphocytic infiltrate of the parathyroid gland to characterize what other authors would have described as parathyroiditis. ${ }^{23-25}$ Because of this terminological variation and the paucity of recent studies, it is not generally clear how to classify inflammatory parathyroid entities.

We start from the general observation that any lymphocytic infiltrate defines a primary inflammatory condition of the involved organ. Genuine organ-related inflammation requires evidence of an organized immune process, e.g. in germinal centres, and/or evidence of immune-mediated cellular or interstitial damage. There are two fundamentally different patterns of distribution of immune cells in the parathyroid gland. The non-specific pattern is marked by perivenular lymphocytic infiltrates without evidence of lymphocyte maturation or immune-mediated tissue damage, such as fibrosis or epithelial degeneration. The pattern of lymphocytic parathyroiditis is defined by interstitial chronic inflammation with mature plasma cells and/or 
Table 2. Lymphocytic infiltrates-large autopsy studies

\begin{tabular}{llllllll}
\hline Study & $\begin{array}{l}\text { No. of } \\
\text { autopsies }\end{array}$ & $\begin{array}{l}\text { No. of } \\
\text { glands } \\
\text { removed }\end{array}$ & $\begin{array}{l}\text { Cases with } \\
\text { lymphocytic } \\
\text { infiltrate, } n(\%)\end{array}$ & $\begin{array}{l}\text { Gender } \\
\text { Male/female, } \\
n\end{array}$ & $\begin{array}{l}\text { Hypoparathyroidism/ } \\
\text { hyperparathyroidism }\end{array}$ & $\begin{array}{l}\text { Associated } \\
\text { diseases* } \\
n(\%)\end{array}$ & $\begin{array}{l}\text { No associated } \\
\text { disease, } \\
n(\%)\end{array}$ \\
\hline Seemann $^{10}$ & 225 & NA & $38(16.9)$ & $21 / 17$ & $\begin{array}{l}2 \times \text { SHPT } \\
0 \times \text { hypoparathyroidism } \\
0 \times \text { pHPT }\end{array}$ & $28(73.7)$ & $10(26.3)$ \\
\hline Thiele $^{36}$ & 589 & 1637 & $4(0.7)$ & - & $\begin{array}{l}10 \times \text { sHPT } \\
0 \times \text { hypoparathyroidism } \\
0 \times \text { pHPT }\end{array}$ & $4(100.0)$ & 0 \\
\hline Reiner $^{24}$ & 144 & 190 & $15(10.4)$ & $7 / 8$ & $0 \times$ PHPT & $12(80.0)$ & $3(20.0)$ \\
\hline
\end{tabular}

NA, Not available; pHPT, primary hyperparathyroidism; sHPT, secondary hyperparathyroidism.

*Associated diseases; these include septicaemia, septic shock, myocardial infraction, and other generalized inflammatory conditions.

germinal centers, along with evidence of epithelial reaction (either degenerative or proliferative). Our reported case clearly documents these defining elements (Figures 2 and 3), along with molecular markers supporting a histiocytic component (CD68 upregulation) in an ischaemic background (HIF1A upregulation) with mitochondrial reaction ( $\mathrm{MDH} 2$ upregulation) and hyperparathyroidism (CA4 upregulation). In light of this definition, we have reviewed all published cases. Lymphocytic infiltrates are not uncommon, and have been identified in $6 \%$ of nearly 1000 autopsy cases in three large series of unselected patients (Tables 2 and 4). They do not seem to relate to functional hyperparathyroidism or hypoparathyroidism, and the autopsies have not identified organ damage related to parathyroid dysfunction. In contrast to this frequent presentation, genuine parathyroiditis is rare (only 15 cases, four of which were identified among 814 autopsy cases, accounting for a total of no more than 0.5\%) (Tables 2-4). If the three cases reported in autopsy case reports are excluded from statistical analysis, the frequency drops to $0.1 \%$. We can safely conclude that genuine parathyroiditis is a very rare condition, on the basis of both autopsy series and the low number of surgical specimens. These surgical specimens were obtained with the aim of curing primary and secondary hyperparathyroidism. We think that the association with parathyroid hyperfunction is spurious and is related to the sampling mechanisms, as parathyroid removal is almost always performed in the setting of hyperfunction.

We conclude that these two patterns are not only morphologically distinct but also pathogenetically different. Lymphocytic infiltrates of the parathyroid gland appear to be statistically associated with systemic disease; this observation is significantly less common in parathyroiditis. We propose that the basis of this finding is directly related to the origin of the lymphocytic infiltrate. It is clearly associated with two conditions that would generally impact on venule integrity of the parathyroid gland, the neck, or beyond. Septicaemia and septic shock are characterized by a loss of integrity of the small vessels caused by bacterial toxins and excessive production of immune mediators by the human body. Depending on the degree of damage, the capillary leak progresses from simple oedema to massive loss of intravascular protein, lymphocytic extravasation, and finally microhaemorrhage into multiple organs. ${ }^{37,38}$ The other condition associated with perivenular diffuse lymphocytic infiltrates is myocardial infarction. Left heart failure leads to right heart failure, venous congestion, increased hydrostatic pressure, and secondary disruption of venule integrity, especially when reduced oxygen delivery enhances tissue vulnerability (Table 6).

The above concept provides significant help in understanding the more frequent non-specific pattern, but it does not shed any light on the origin of the primary parathyroid immune process. The nature of the current data does not invite any related speculations. Perhaps the most remarkable observation of this study is the rarity of specific inflammatory processes in the parathyroid gland. This in striking contrast to the neighbouring endocrine organ, i.e. the thyroid, where autoimmune or perhaps infection-related thyroiditis is observed with a lifetime incidence of $\sim 10 \%{ }^{2,5}$ For some reason, the parathyroid gland is either poorly antigenic or protected against the processes that initiate so-called autoimmunity. The latter observation could become relevant in the perspective of transplantation of small cell volumes. 


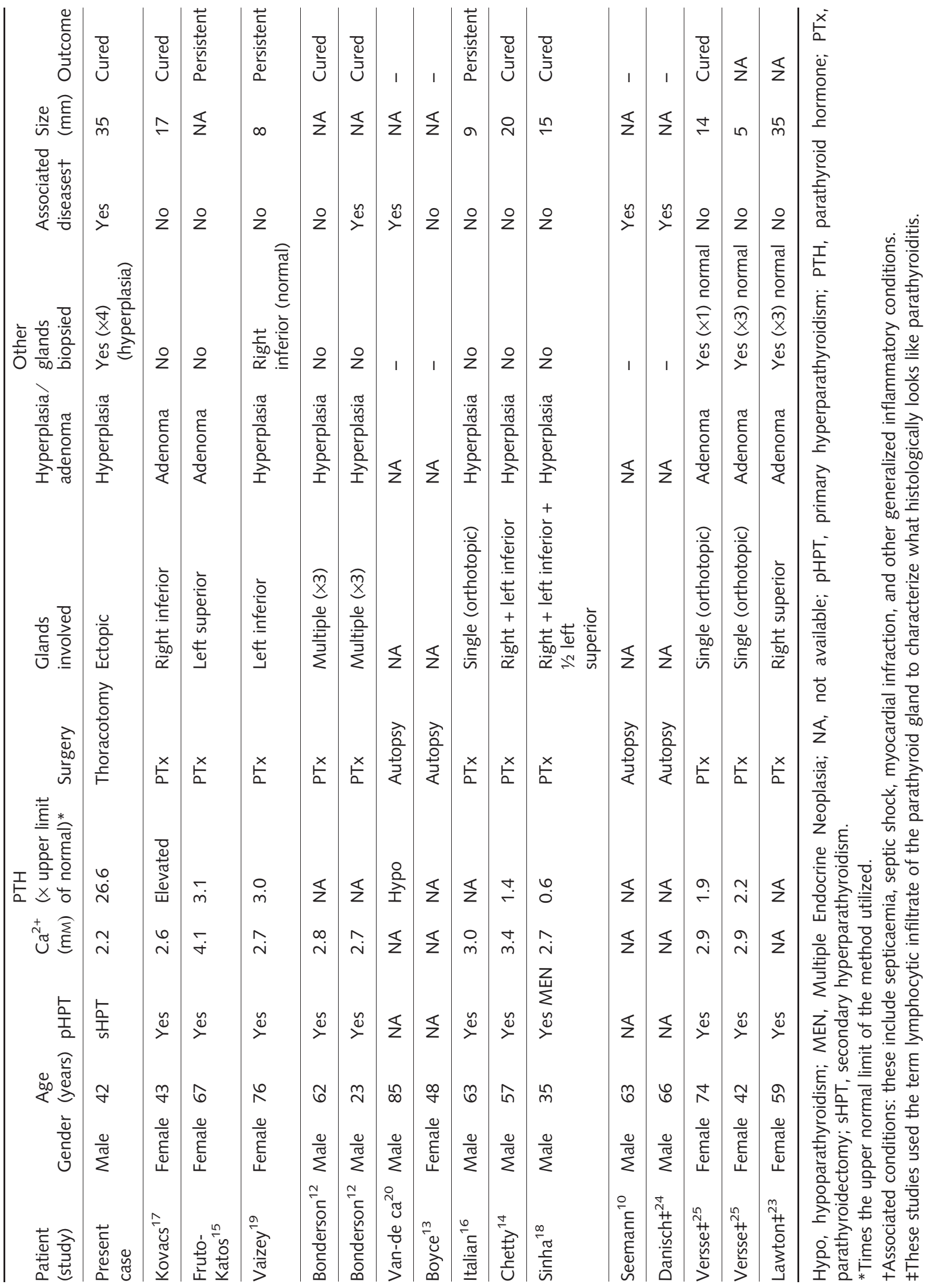




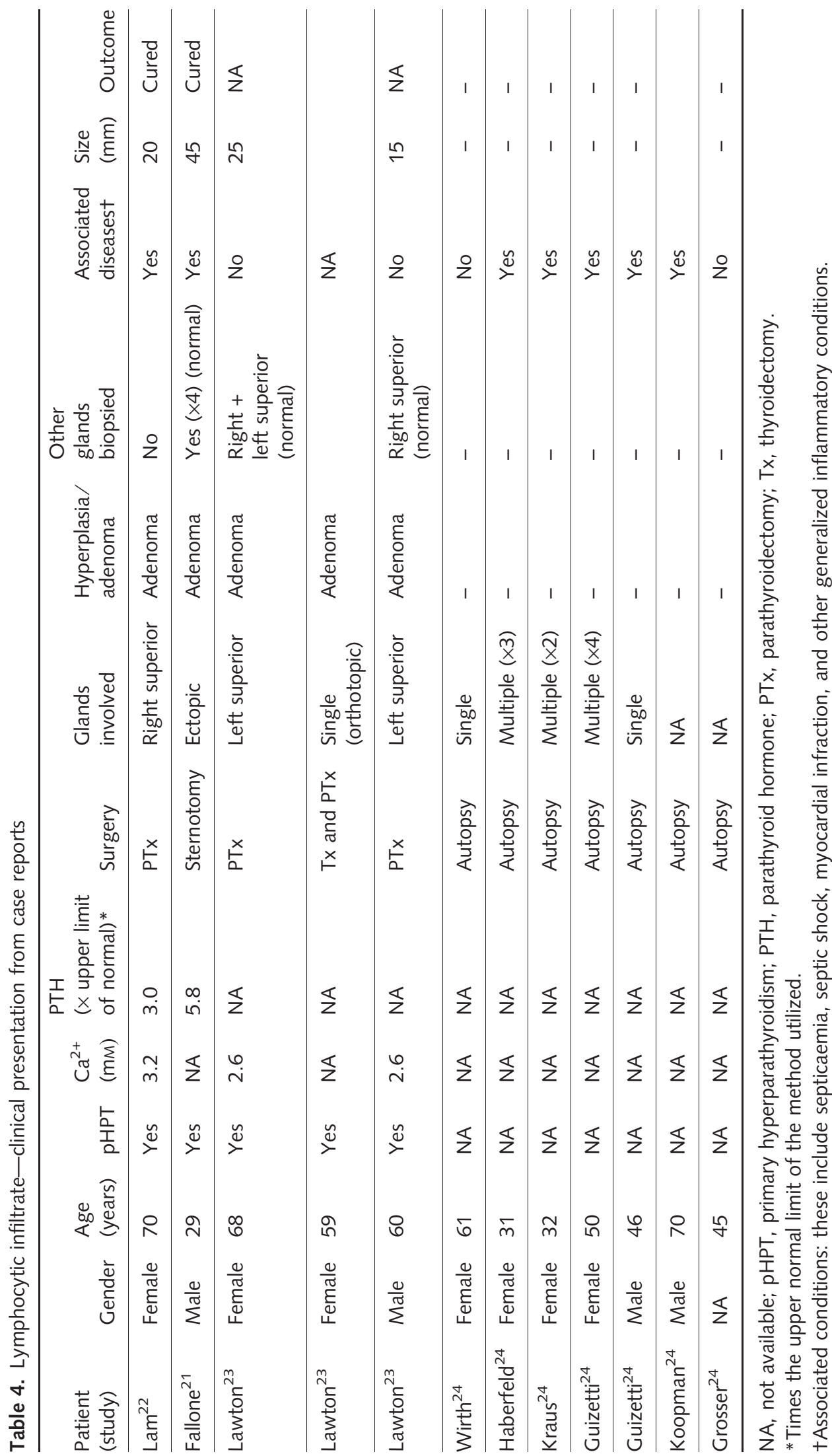




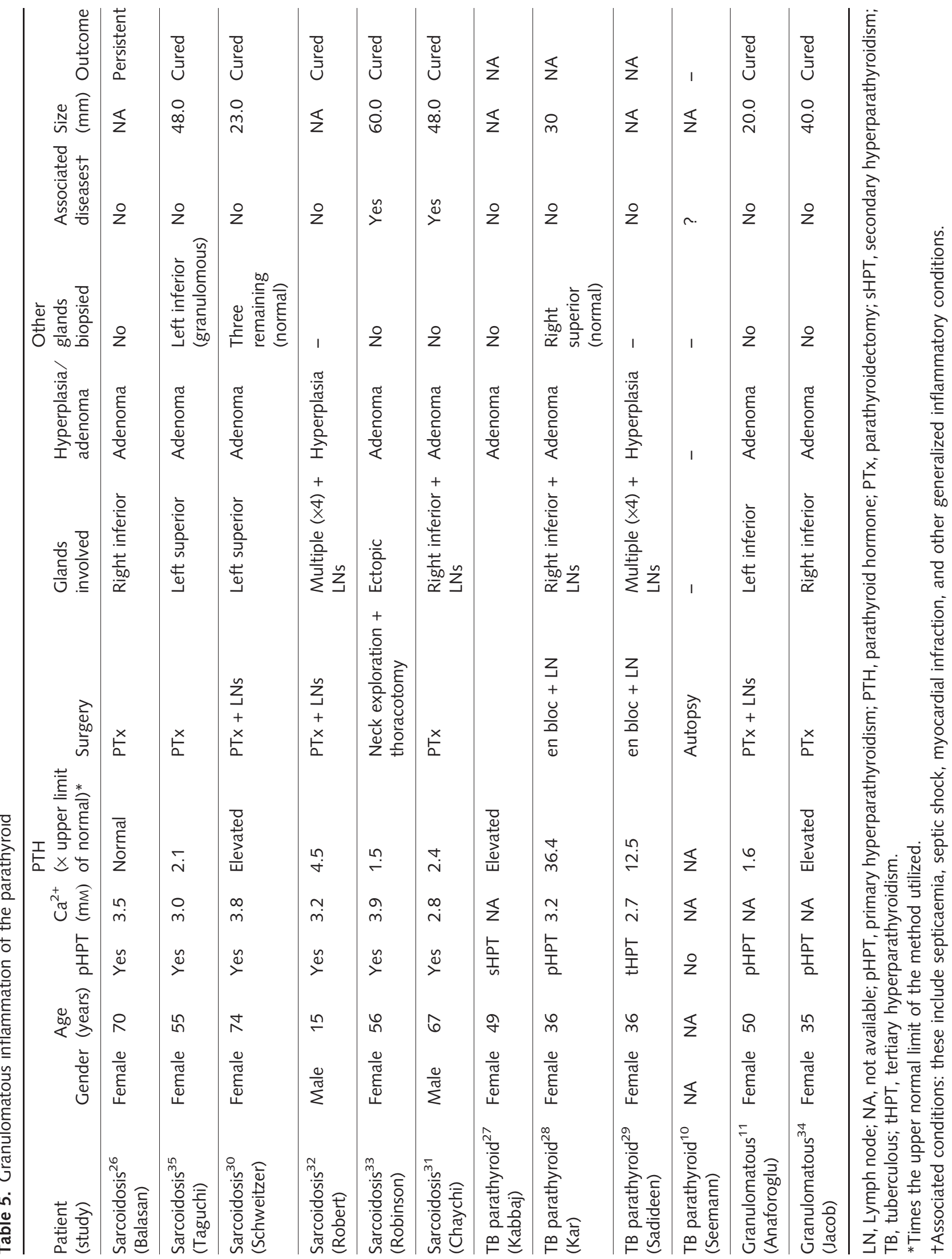




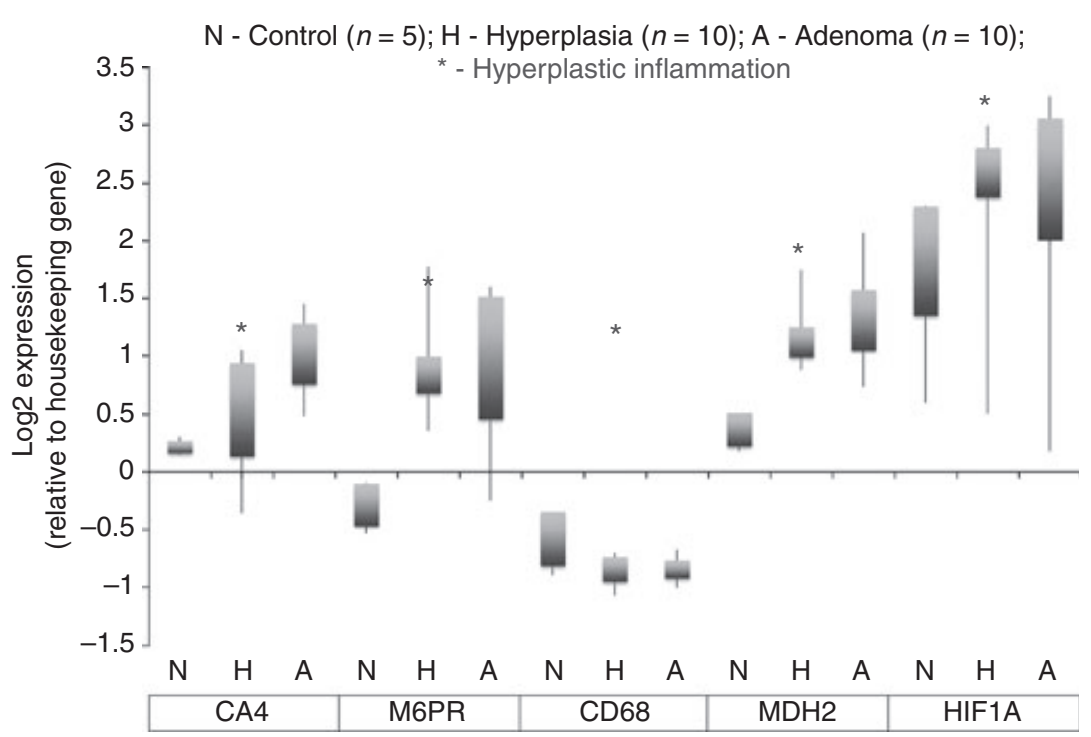

Figure 4. Relative gene expression for each marker.

Table 6. Association of underlying diseases with lymphocytic infiltration and true parathyroiditis

\begin{tabular}{lllll}
\hline Diagnosis & Patients, $n$ & Associated disease, $n(\%)$ & No associated disease, $n(\%)$ & $P$-value \\
\hline Lymphocytic infiltrates & 69 & $51(73.9)$ & $17(24.6)$ & $<0.001$ \\
\hline Parathyroiditis & 16 & $5(31.2)$ & $11(68.7)$ & \\
\hline
\end{tabular}

We also identified 14 cases of granulomatous inflammation of the parathyroid gland, including six cases of sarcoidosis, four cases of tuberculosis, and two nonspecific granulomatous processes (Table 5). Again, the rarity of this association warrants attention when seen on the background of thousands or millions of described cases of granulomatous processes in other tissues. ${ }^{1,39,40}$

We agree with Furuto-Kato ${ }^{15}$ that parathyroiditis may be associated with significant functional aberrations (Figure 1); an explanation of this observation is offered by molecular studies showing the impact of inflammatory substances on functional regulation of the parathyroid gland. ${ }^{41,42}$ Such immune mediators could plausibly be liberated and act as paracrine regulators in the vicinity, for example, of germinal centres of the parathyroid chief cell mass.

\section{Conclusion}

Genuine inflammatory disorders of the parathyroid gland are rare, and may result in functional dysregulation. The term parathyroiditis should be reserved for lesions with evidence of a primary parathyroid immune process. The common lymphocytic infiltrate is a non-organ-specific reflection of a capillary permeability change and, at best, indicates clinical disease. The diagnosis of lymphocytic infiltrate as such should not lead to any other examinations or diagnostic procedures. The rarity of granulomatous disease in the parathyroid gland points to specific immunological properties of the parathyroid gland.

\section{Disclosure statement}

The authors declare that there is no conflict of interest that would prejudice the impartiality of this scientific work.

\section{References}

1. Bulbuloglu E, Ciralik H, Okur E, Ozdemir G, Ezberci F, Cetinkaya A. Tuberculosis of the thyroid gland: review of the literature. World J. Surg. 2006; 30; 149-155.

2. Hollowell JG, Staehling NW, Flanders WD et al. Serum TSH, T(4), and thyroid antibodies in the United States population (1988 to 1994): National Health and Nutrition Examination Survey (NHANES III). J. Clin. Endocrinol. Metab. 2002; 87; 489-499.

3. Carpinteri R, Patelli I, Casanueva FF, Giustina A. Pituitary tumours: inflammatory and granulomatous expansive lesions of the pituitary. Best Pract. Res. Clin. Endocrinol. Metab. 2009; 23; 639-650.

4. Lam KY, Lo CY. A critical examination of adrenal tuberculosis and a 28-year autopsy experience of active tuberculosis. Clin. Endocrinol. (Oxf.) 2001; 54; 633-639. 
5. Li Y, Nishihara E, Kakudo K. Hashimoto's thyroiditis: old concepts and new insights. Curr. Opin. Rheumatol. 2011; 23; 102-107.

6. Gonzalez Gonzalez A, Recio Cordov JM, Rodriguez-Garcia JL, Velasco Romero AM, Rubio Herrera MA. Episodes of thyrotoxicosis in Hashimoto's thyroiditis. Minerva Endocrinol. 2010; 35; $35-36$.

7. Kifor O, McElduff A, LeBoff MS et al. Activating antibodies to the calcium-sensing receptor in two patients with autoimmune hypoparathyroidism. J. Clin. Endocrinol. Metab. 2004; 89; 548-556.

8. Kifor O, Moore FD Jr, Delaney M et al. A syndrome of hypocalciuric hypercalcemia caused by autoantibodies directed at the calciumsensing receptor. J. Clin. Endocrinol. Metab. 2003; 88; 60-72.

9. Brown EM. Anti-parathyroid and anti-calcium sensing receptor antibodies in autoimmune hypoparathyroidism. Endocrinol. Metab. Clin. North Am. 2009; 38; 437-445.

10. Seemann N. Studies on the frequency of lymphocytic parathyroiditis. Dtsch. Med. Wochenschr. 1967; 92; 106-108.

11. Anaforoglu I, Siviloglu C, Livaoglu A, Algun E. Granulomatous infiltration of a parathyroid adenoma presenting as primary hyperparathyroidism in a woman: a case report. J. Med. Case Reports 2010; 400; 1-4.

12. Bondeson AG, Bondeson L, Ljungberg O. Chronic parathyroiditis associated with parathyroid hyperplasia and hyperparathyroidism. Am. J. Surg. Pathol. 1984; 8; 211-215.

13. Boyce BF, Doherty VR, Mortimer G. Hyperplastic parathyroiditis-a new autoimmune disease? J. Clin. Pathol. 1982; 35; 812814.

14. Chetty R, Forder MD. Parathyroiditis associated with hyperparathyroidism and branchial cysts. Am. J. Clin. Pathol. 1991; 96; $348-350$

15. Furuto-Kato S, Matsukura S, Ogata M et al. Primary hyperparathyroidism presumably caused by chronic parathyroiditis manifesting from hypocalcemia to severe hypercalcemia. Intern. Med. 2005; 44; 60-64.

16. Pizzolitto S, Rizzi C, Bacchi G, Floretti G. Chronic hyperplastic parathyroiditis: the anatomico-clinical and pathogenetic aspects. Acta Otorhinolaryngol. Ital. 1991; 11; 505-509.

17. Kovacs K, Bell CD, Juco J, Rotondo F, Anderson J. Parathyroid chief cell adenoma associated with massive chronic parathyroiditis in a woman with hyperparathyroidism. Endocr. Pathol. 2007; 18 ; $42-45$.

18. Sinha SN, McArdle JP, Shepherd JJ. Hyperparathyroidism with chronic parathyroiditis in a multiple endocrine neoplasia patient. Aust. N. Z. J. Surg. 1993; 63; 981-982.

19. Vaizey CJ, Ali M, Gilbert JM. Chronic parathyroiditis associated with primary hyperplastic hyperparathyroidism. J. R. Soc. Med. 1997; 90; 336-337.

20. Van de Casseye M, Gepts W. Case report: primary (autoimmune?) parathyroiditis. Virchows Arch. A Pathol. Pathol. Anat. 1973; 361; 257-261.

21. Fallone E, Bourne PA, Watson TJ, Ghossein RA, Travis WD, Xu H. Ectopic (mediastinal) parathyroid adenoma with prominent lymphocytic infiltration. Appl. Immunohistochem. Mol. Morphol. 2009; 17; 82-84.

22. Lam KY, Chan AC, Lo CY. Parathyroid adenomas with pronounced lymphocytic infiltration: no evidence of autoimmune pathogenesis. Endocr. Pathol. 2000; 11; 77-83.

23. Lawton TJ, Feldman M, LiVolsi VA. Lymphocytic infiltrates in solitary parathyroid adenomas - a report of four cases with review of the literature. Int. J. Surg. Pathol. 1998; 6; 5-9.

24. Reiner L, Klayman MJ, Cohen RB. Lymphocytic infiltration of the parathyroid glands. Jew. Mem. Hosp. Bull. 1962; 7; 103-118.
25. Veress B, Nordenstrom J. Lymphocytic infiltration and destruction of parathyroid adenomas: a possible tumour-specific autoimmune reaction in two cases of primary hyperparathyroidism. Histopathology 1994; 25; 373-377.

26. Balasanthiran A, Sandler B, Amonoo-Kuofi K, Swamy R, Kaniyur S, Kaplan F. Sarcoid granulomas in the parathyroid gland - a case of dual pathology: hypercalcaemia due to a parathyroid adenoma and coexistent sarcoidosis with granulomas located within the parathyroid adenoma and thyroid gland. Endocr J. 2010; 57; 603-607.

27. Kabbaj DE, Oualim Z. Parathyroid gland tuberculosis associated with secondary hyperparathyroidism in hemodialysis patient. Saudi J. Kidney Dis. Transpl. 2010; 21; 742-743.

28. Kar DK, Agarwal G, Mehta B et al. Tuberculous granulomatous inflammation associated with adenoma of parathyroid gland manifesting as primary hyperparathyroidism. Endocr. Pathol. 2001; 12; 355-359.

29. Sadideen HM, Blaker P, O'Donnell P, Taylor J, Goldsmith DJ. Tuberculosis complicating tertiary hyperparathyroidism in a patient with end-stage renal disease: a case report. J. Nephrol. $2008 ; 21 ; 438-441$.

30. Schweitzer VG, Thompson NW, Clark KA, Nishiyama RH, Bigos ST. Sarcoidosis, hypercalcemia and primary hyperparathyroidism. The vicissitudes of diagnosis. Am J Surg. 1981; 142; 499-503.

31. Chaychi L, Chaidarun S, Golding A, Kinlaw WB, Memoli V, Siegel A. Unusual recurrence of hypercalcemia due to concurrent parathyroid adenoma and parathyroid sarcoidosis with lymph node involvement. Endocr. Pract. 2010; 16; 463-467.

32. Bohnen RF, Jubiz W, Rallison M, Stevens LE, Tyler FH. Sarcoidosis and autonomous parathyroid hyperplasia. JAMA $1971 ; 217 ; 1385-1387$.

33. Robinson RG, Kerwin DM, Tsou E. Parathyroid adenoma with coexistent sarcoid granulomas. A hypercalcemic patient. Arch. Intern. Med. 1980; 140; 1547-1548.

34. Jacob PM, Sukumar GC, Nair A, Thomas S. Parathyroid adenoma with necrotizing granulomatous inflammation presenting as primary hyperparathyroidism. Endocr. Pathol. 2005 Summer; 16; 157-160.

35. Taguchi K, Makimoto K, Nagai S, Kitaichi M, Izumi T, Yamabe H. Cystic parathyroid adenoma with coexistent sarcoid granulomas. Arch. Otorhinolaryngol. 1987; 243; 392-394.

36. Thiele J, Ries P, Georgii A. Special and functional pathomorphology of parathyroid glands as revealed in non-selected autopsies (589 cases). Virchows Arch. A Pathol. Anat. Histol. $1975 ; 367 ; 195-208$

37. Gustot T. Multiple organ failure in sepsis: prognosis and role of systemic inflammatory response. Curr. Opin. Crit. Care 2011; 17; 153-159.

38. van der Flier M, van Leeuwen HJ, van Kessel KP, Kimpen JL, Hoepelman AI, Geelen SP. Plasma vascular endothelial growth factor in severe sepsis. Shock 2005; 23; 35-38.

39. Bonfioli AA, de Miranda SS, Campos WR, Orefice F. Tuberculosis. Semin. Ophthalmol. 2005; 20; 169-175.

40. Margolis R, Lowder CY. Sarcoidosis. Curr. Opin. Ophthalmol. 2007; 18; 470-475.

41. Rodriguez M, Canadillas S, Lopez I, Aguilera-Tejero E, Almaden Y. Regulation of parathyroid function in chronic renal failure. J. Bone Miner. Metab. 2006; 24; 164-168.

42. Arnold A, Shattuck TM, Mallya SM et al. Molecular pathogenesis of primary hyperparathyroidism. J. Bone Miner. Res. 2002; 17(Suppl. 2); N30-N36. 